\title{
Postprandial thermogenesis and substrate utilization after ingestion of different dietary carbohydrates.
}

Citation for published version (APA):

Blaak, E. E., \& Saris, W. H. M. (1996). Postprandial thermogenesis and substrate utilization after ingestion of different dietary carbohydrates. Metabolism-Clinical and Experimental, 45(10), 1235-1242.

https://doi.org/10.1016/S0026-0495(96)90241-3

Document status and date:

Published: 01/01/1996

DOI:

10.1016/S0026-0495(96)90241-3

Document Version:

Publisher's PDF, also known as Version of record

\section{Please check the document version of this publication:}

- A submitted manuscript is the version of the article upon submission and before peer-review. There can be important differences between the submitted version and the official published version of record.

People interested in the research are advised to contact the author for the final version of the publication, or visit the DOI to the publisher's website.

- The final author version and the galley proof are versions of the publication after peer review.

- The final published version features the final layout of the paper including the volume, issue and page numbers.

Link to publication

\footnotetext{
General rights rights.

- You may freely distribute the URL identifying the publication in the public portal. please follow below link for the End User Agreement:

www.umlib.nl/taverne-license

Take down policy

If you believe that this document breaches copyright please contact us at:

repository@maastrichtuniversity.nl

providing details and we will investigate your claim.
}

Copyright and moral rights for the publications made accessible in the public portal are retained by the authors and/or other copyright owners and it is a condition of accessing publications that users recognise and abide by the legal requirements associated with these

- Users may download and print one copy of any publication from the public portal for the purpose of private study or research.

- You may not further distribute the material or use it for any profit-making activity or commercial gain

If the publication is distributed under the terms of Article $25 \mathrm{fa}$ of the Dutch Copyright Act, indicated by the "Taverne" license above, 


\title{
Postprandial Thermogenesis and Substrate Utilization After Ingestion of Different Dietary Carbohydrates
}

\author{
E.E. Blaak and W.H.M. Saris
}

\begin{abstract}
Whole-body thermogenesis, substrate utilization (open-circuit ventilated-hood system), and exogenous carbohydrate oxidation were evaluated in 10 healthy lean male volunteers (aged $27.8 \pm 2.5$ years) for $\mathbf{6}$ hours after oral ingestion of $75 \mathrm{~g}$ naturally enriched fructose, glucose (both derived from corn starch), cane sugar, and a good digestible corn starch (all mixed with $400 \mathrm{~mL}$ water). The integrated areas under the glucose and insulin response curves above baseline were highest with glucose and starch, intermediate with sucrose, and lowest with fructose, whereas there were no significant differences in the integrated nonesterified fatty acid (NEFA) response between carbohydrates. The total increment in energy expenditure (EE) above baseline was similar with fructose $(130 \pm 24 \mathrm{~kJ} / 6 \mathrm{~h})$ and sucrose $(141 \pm 17 \mathrm{~kJ} / 6 \mathrm{~h})$, was higher with sucrose as compared with starch (108 $\pm 24 \mathrm{~kJ} / 6 \mathrm{~h}, P<.05)$ and glucose $(94 \pm 20 \mathrm{~kJ} / 6 \mathrm{~h}, P<.05)$, and tended to be higher with fructose as compared with glucose $\{P=.059)$. Both the increment in total carbohydrate oxidation $(P<.05)$ and the increment in exogenous carbohydrate oxidation $(P<.01)$ were significantly higher with fructose and sucrose compared with glucose and starch. The initial inhibition of lipid oxidation was higher with sucrose and fructose than with glucose and starch, whereas the integrated decrement in lipid oxidation over 6 hours was only higher with fructose compared with glucose and starch $(P<.05)$. In conclusion, thermogenesis and substrate utilization vary considerably after ingestion of different types of carbohydrate in young lean males, indicating that the carbohydrate composition of the diet may have important consequences for energy and macronutrient balance.
\end{abstract}

Copyright $\odot 1996$ by W.B. Saunders Company

$\mathbf{T}^{\mathrm{H}}$ HERE IS INCREASING evidence that the macronutrient composition of the diet, particularly carbohydrates and fats, plays an important role in the maintenance of energy balance and thus in the regulation of body weight, ${ }^{1,2}$ since the body has a limited capacity to regulate fat balance as compared with carbohydrate balance. The body's glycogen stores are relatively small, and (evolutionally) mechanisms have developed to efficiently adjust carbohydrate intake to oxidation. In contrast, fat intake has little effect on fat oxidation, ${ }^{3}$ and it has been suggested that the body's carbohydrate economy is a more important determinant of fat oxidation than fat intake. ${ }^{2}$ Adjustment of fat oxidation to fat intake may occur over time, since a positive fat balance over a longer period leads to increased fat storage, which can subsequently alter insulin sensitivity, circulating free fatty acid levels, and thus fat oxidation.

In the debate on the role of carbohydrate and fat metabolism in body weight maintenance, little attention has been given to the type of carbohydrate. Wide variations exist in absorption rates of carbohydrates, which may be responsible for variations in postprandial glycemic and insulinemic responses. ${ }^{4}$ These differences in postprandial hormonal and nutrient profiles may affect the rate of glucose disposal in the cell (oxidation or synthesis), the rate of fat oxidation, and the magnitude of thermogenic response, and may consequently be significant for daily energy and substrate balance. Previous studies have reported different thermogenic effects after ingestion of several dietary carbohydrates. Postprandial thermogenesis is higher after fructose $\mathrm{e}^{5-7}$ or sucrose $\mathrm{s}^{8}$ as compared with glucose ingestion. Additionally, after fructose intake, a higher increase in carbohydrate oxidation and a more pronounced suppression of lipid oxidation have been reported. ${ }^{5-7}$ Furthermore, the carbohydrate to fat oxidation ratio has been reported to be higher after ingestion of cooked manioc starch (16\% amylose) than after ingestion of glucose. ${ }^{9}$ So far, no data are available that systematically compare the effects of more than two types of carbohy- drates on postprandial thermogenesis and substrate utilization.

The present study was therefore intended to investigate the impact of glucose, fructose, sucrose, and starch on postprandial glucose and insulin responses, energy expenditure (EE), and postprandial substrate utilization in young lean male volunteers. All carbohydrates were derived from naturally ${ }^{13} \mathrm{C}$-enriched plants, which made it possible to determine the amount of ingested carbohydrate that was directly oxidized (exogenous carbohydrate oxidation) from ${ }^{13} \mathrm{CO}_{2}$ enrichment in expired air.

\section{SUBJECTS AND METHODS}

\section{Subjects}

Ten men with a mean age of $27.8 \pm 2.5$ years were studied. The mean body weight was $74.9 \pm 2.0 \mathrm{~kg}$, and mean height and body fat percentage were $186.1 \pm 2.5 \mathrm{~cm}$ and $13.0 \% \pm 1.2 \%$, respectively. The subjects were all healthy and took no medication. Furthermore, they spent no more than 4 hours per week in organized sports activities.

The study was reviewed and approved by the Ethics Committee of the University of Limburg.

\section{Design}

The experiments were performed at 8 AM after a 12-hour overnight fast, with the subjects resting semisupine. The subjects were studied on four occasions with an interval of at least 1 week, and came to the laboratory by car or bus. The order of the treatments was randomized.

At the beginning of an experiment, a cannula was inserted into

From the Department of Human Biology, University of Limburg, Maastricht, The Netherlands.

Submitted November 20, 1995; accepted April 30, 1996.

Supported by a grant from the Dutch Sugar Foundation.

Address reprint requests to E.E. Blaak, PhD, Department of Human Biology, University of Limburg, PO Box 616, 6200 MD Maastricht, The Netherlands.

Copyright $₫ 1996$ by W.B. Saunders Company

0026-0495/96/4510-0008\$03.00/0 
an antecubital vein. During the entire experiment, whole-body EE, $\mathrm{O}_{2}$ consumption $\left(\dot{\mathrm{V}}_{2}\right), \mathrm{CO}_{2}$ production $\left(\dot{\mathrm{V}}_{\mathrm{CO}_{2}}\right)$, and the respiratory exchange ratio were measured by means of an open-circuit ventilated-hood system (Department of Human Biology, University of Limburg, Maastricht, The Netherlands). The precision of gas analyzers and the calibration procedures were periodically checked by methanol (Merck, Darmstadt, Germany) combustion tests of an average of 21 hours' duration (range, 1 to 4 ). The respiratory exchange ratio for a total of 40 methanol combustion tests was found to be $0.676 \pm 0.001$ (range, 0.650 to 0.690 ) with a coefficient of variation of $1.2 \%$. Oxygen was overestimated, on average, by $1.1 \% \pm 0.3 \%$ (range, $-4.6 \%$ to $4.1 \%$ ) and carbon dioxide by $1.3 \% \pm 0.3 \%$. A measurement of resting EE was started 30 minutes after insertion of the cannula. After a 30-minute baseline measurement, the carbohydrate load was ingested within 10 minutes.

The carbohydrate load consisted of $75 \mathrm{~g}$ anhydrous carbohydrate equivalents in the form of glucose, fructose, sucrose, and corn starch. All carbohydrates were derived from naturally ${ }^{13} \mathrm{C}$-enriched sources: glucose (Meritose, ${ }^{13} \mathrm{C}$ enrichment $=-11.67$ per part per thousand [mil] $v$ Pee Dee Belemate limestone [PDB]; Amylum, Aalst, Belgium) and fructose (Krystar $300,{ }^{13} \mathrm{C}$ enrichment $=-10.39$ per mil $v$ PDB; Amylum) were derived from corn starch, sucrose was derived from sugar cane $\left({ }^{13} \mathrm{C}\right.$ enrichment $=-10.67$ per mil $v$ $\mathrm{PDB}$ ), and the starch was a pregelatinized good digestible corn starch (Merigum, 27\% amylose and $73 \%$ amylopectin, ${ }^{13} \mathrm{C}$ enrichment $=-10.57$ per mil $v$ PDB; Amylum). All carbohydrates were mixed with $400 \mathrm{~mL}$ water, and the glucose, fructose, and sucrose load were lemon-flavored and $1 \mathrm{~mL}$ artificial sweetener (saccharine, cyclamate) was added to the starch load for taste improvement. The subjects were instructed to avoid nutrient sources potentially containing naturally enriched carbohydrates from $\mathrm{C}_{4}$ plants for at least 1 week before the start of the experiments.

After ingestion of the carbohydrate load, the canopy was put back in place and EE and respiratory exchange were evaluated for another 6 hours. At baseline, every half-hour during the first 3 hours postprandially, and every hour during the last 3 hours postprandially, blood samples were taken for determination of plasma nonesterified fatty acids (NEFAs), glucose, and insulin concentrations. At baseline and every hour postprandially, the ventilated-hood measurement was interrupted for 5 minutes to collect an expired-air sample. Expired-air samples were obtained by having the subjects breath normally for 3 minutes into a mouthpiece connected to a $6.75-\mathrm{L}$ mixing chamber and then collecting a sample into a $20-\mathrm{mL}$ vacutainer tube. Urine was collected overnight before the experiment and once during (immediately after collection of expired air) and once after the experiment for determination of urinary nitrogen to calculate the nonprotein respiratory exchange ratio.

\section{Sample Analyses}

Plasma glucose and NEFAs were determined using enzymatic assays automated on a Cobas Bio centrifugal analyzer at $340 \mathrm{~nm}$, using standard kits (for glucose, Roche Diagnostics, Hoffman-La Roche, Basel, Switzerland; for NEFA, NEFA C, Wako, Chemicals, Neuss, Germany). Plasma insulin was determined using a doubleantibody radioimmunoassay for human insulin (Kabi Pharmacia Diagnostics, Uppsala Sweden). The ${ }^{13} \mathrm{C} /{ }^{12} \mathrm{C}$ ratio in expired $\mathrm{CO}_{2}$ was measured with a Finnigan isotope ratio mass spectrometer (Bremen, Germany). ${ }^{10}$

\section{Calculations}

Gas exchange monitoring. The metabolic rate was calculated from $\dot{\mathrm{VO}}_{2}$ and $\mathrm{VCO}_{2}$ according to the equations of Weir. ${ }^{11}$ Carbohy- drate and fat oxidation rates were calculated from $\dot{\mathrm{V}}_{2}$ and $\dot{\mathrm{V}}_{2}$ and urinary nitrogen excretion. The amount of protein oxidized was estimated from total urinary nitrogen excretion, since most urinary nitrogen $(>80 \%)$ is in the form of urea, with $1 \mathrm{~g}$ nitrogen arising from approximately $6.25 \mathrm{~g}$ protein. Carbohydrate (c) and fat (f) oxidation rates were calculated according to the following equations using values for gas exchange from the table reported by Carpenter as described by Brouwer ${ }^{12}: \mathrm{c}=4.170 \dot{\mathrm{V}}_{2}-2.965 \dot{\mathrm{V}}_{2}$ $-2.438 \mathrm{n}$ and $\mathrm{f}=1.718 \mathrm{VO}_{2}-1.718 \dot{\mathrm{V}}_{\mathrm{CO}_{2}}-1.969 \mathrm{n}$. $\mathrm{VO}_{2}$ and $\dot{\mathrm{V}}_{\mathrm{CO}_{2}}$ are in liters per minute, and $n$ is nitrogen excretion in urine in grams per minute. With values for the nonprotein respiratory quotient more than 1.00 , negative values for net lipid oxidation are obtained. However, it has been calculated that these negative values are numerically equivalent to the net amount of lipid synthesized (lipogenesis) and that they do not invalidate the calculation of other substrate oxidation rates. ${ }^{13}$

Exogenous carbohydrate oxidation. Exogenous carbohydrate oxidation was calculated by determining the mean volume of $\mathrm{CO}_{2}$ exhaled and the ${ }^{13} \mathrm{C} /{ }^{12} \mathrm{C}$ enrichment of ingested carbohydrate ( $\delta^{13} \mathrm{Cing}$ ) and expired $\mathrm{CO}_{2}$, as previously described by Mosora et al. ${ }^{14}$ For each hour, the fractional part of the volume of exhaled $\mathrm{CO}_{2}$ resulting from external glucose can be calculated as follows: $\dot{\mathrm{V}} \mathrm{CO}_{2}$ from exogenous carbohydrate at nth hour $=\dot{\mathrm{VCO}}_{2}$ at $\mathrm{nth}$ hour $\times\left(\delta^{13} \mathrm{C}_{\text {post }}\right.$ at nth hour $\left.-\delta^{13} \mathrm{C}_{\text {rest }}\right) /\left(\delta^{13} \mathrm{C}_{\text {Test }}-\delta^{13} \mathrm{C}_{\text {ing }}\right)$, where $\delta^{13} \mathrm{C}_{\text {rest }}$ and $\delta^{13} \mathrm{C}_{\text {post }}$ are baseline and postprandial enrichment(s), respectively. Subsequently, exogenous carbohydrate $(\mathrm{CHO})$ oxidation can be calculated: exogenous $\mathrm{CHO}$ oxidized at nth hour $(\mathrm{g})=$ $\dot{\mathrm{V}} \mathrm{CO}_{2}$ from exogenous $\mathrm{CHO}$ at nth hour $(\mathrm{L}) \times 1.34 \mathrm{~g} \mathrm{CHO} / \mathrm{L} \mathrm{CO}_{2}$.

\section{Statistics}

Results are presented as the mean $\pm \mathrm{SE}$. To indicate significant changes in the response pattern after ingesting a carbohydrate source, a nonparametric ANOVA or Friedman's test was used. For statistical comparisons between carbohydrates, responses were calculated as integrated areas under the curve. Differences between responses to the different carbohydrates were analyzed with Friedman's test. In the case of significance, posthoc testing was performed with a Wilcoxon ranked test for paired comparisons.

\section{RESULTS}

\section{Plasma Glucose, Insulin, and NEFAs}

Basal levels of glucose, NEFAs, and insulin were comparable in the four experiments (Figs 1 and 2).

Carbohydrate ingestion resulted in an increase in plasma glucose levels (for all carbohydrates, [ANOVA] $P<.001$; Fig 1). Peak glucose levels after ingestion of glucose (at 30 minutes), sucrose (at 30 minutes), and starch (at 60 minutes) were not significantly different and were all higher than the peak glucose levels obtained after fructose ingestion (at 30 minutes; $P<.01$ ). After the initial increase in glycemic response, glucose levels returned to baseline at 60 minutes with fructose, at 90 minutes with glucose and sucrose, and at 120 minutes with starch. Plasma glucose values were less than baseline from 150 to 300 minutes with glucose and sucrose (at all time points, $P<.05$ ) and from 240 to 300 minutes with fructose $(P<.05)$, whereas with starch the values remained at baseline levels from 2 to 6 hours postprandially. Integrating the glycemic response over 6 hours postprandially showed significant differences between the carbohydrates (ANOVA, $P=.03$ ). The integrated glycemic response above baseline over 6 hours 
postprandially was higher with glucose and starch than with fructose, with an intermediate position for sucrose (Fig 1).

After all carbohydrate loads, plasma insulin levels changed (for all carbohydrates, $P<.001$ ). Peak insulin levels were highest with glucose (at 30 minutes, $73.7 \pm 15.7 \mathrm{mU} / \mathrm{L}$, $P<.01 v$ other carbohydrates), intermediate with starch and sucrose (starch at 60 minutes, $49.5 \pm 12.4$, and sucrose at 30 minutes, $51.5 \pm 10.4 \mathrm{mU} / \mathrm{L}$ ), and lowest with fructose (at 30 minutes, $23.7 \pm 4.0 \mathrm{mU} / \mathrm{L}, P<.05 v$ other carbohydrates). Insulin values returned to control levels at 150 minutes for fructose and sucrose, at 180 minutes for glucose, and at 240 minutes for starch, and decreased to less than control values $(P<.05)$ from 240 to 360 minutes for fructose, glucose, and sucrose and at 360 minutes for starch $(P<.05)$. There were significant differences in the integrated area under the curve above baseline for the insulin response (ANOVA, $P<.001$ ). The increment in the integrated area under the insulin response curve was highest for glucose, intermediate for starch and sucrose, and lowest for fructose (Fig 1).

After carbohydrate ingestion, there were significant changes in plasma NEFA levels (for all carbohydrate loads, $P<.001)$. For all types of carbohydrates, there was a decline in plasma NEFA levels from 0 to 180 minutes postprandially (at all time points, $P<.05$; Fig 2 ). After a return to baseline levels, NEFA values increased at 360 minutes for fructose, sucrose, and starch $(P<.05)$ and from 300 to 360 minutes for glucose (at both time points, $P<.05$ ). The net decrement in plasma NEFA levels tended to be most pronounced with fructose, but differences in integrated values of the different carbohydrates did not reach statistical significance (Fig 2). An overview of the increments in integrated changes in plasma glucose, insulin, and NEFAs is shown in Table 1.

\section{$E E$}

Resting EE was similar in the four experiments $(5.453 \pm 0.153 \mathrm{~kJ} / \mathrm{min})$. After carbohydrate ingestion, there was a significant increase in EE for all carbohydrates (ANOVA, $P<.001$; Fig 3). The peak increase in EE was higher with sucrose as compared with glucose, fructose, and starch $(P<.05)$. Values for EE returned to baseline for sucrose at 150 minutes, for glucose and starch at 180 minutes, and for fructose at 210 minutes, and remained insignificantly different from control values during the rest of the experiment. There were significant differences in the integrated increments in $\mathrm{EE}$ above baseline between different carbohydrates $(P=.016)$. The total increment in EE above baseline was similar with fructose and sucrose and higher with sucrose as compared with starch and glucose ( $P<.05$ and $P<.01$, respectively), and tended to be higher with fructose as compared with glucose $(P=.059)$. Expressing the thermogenic response as a percentage of the energy content of the administered carbohydrate yielded
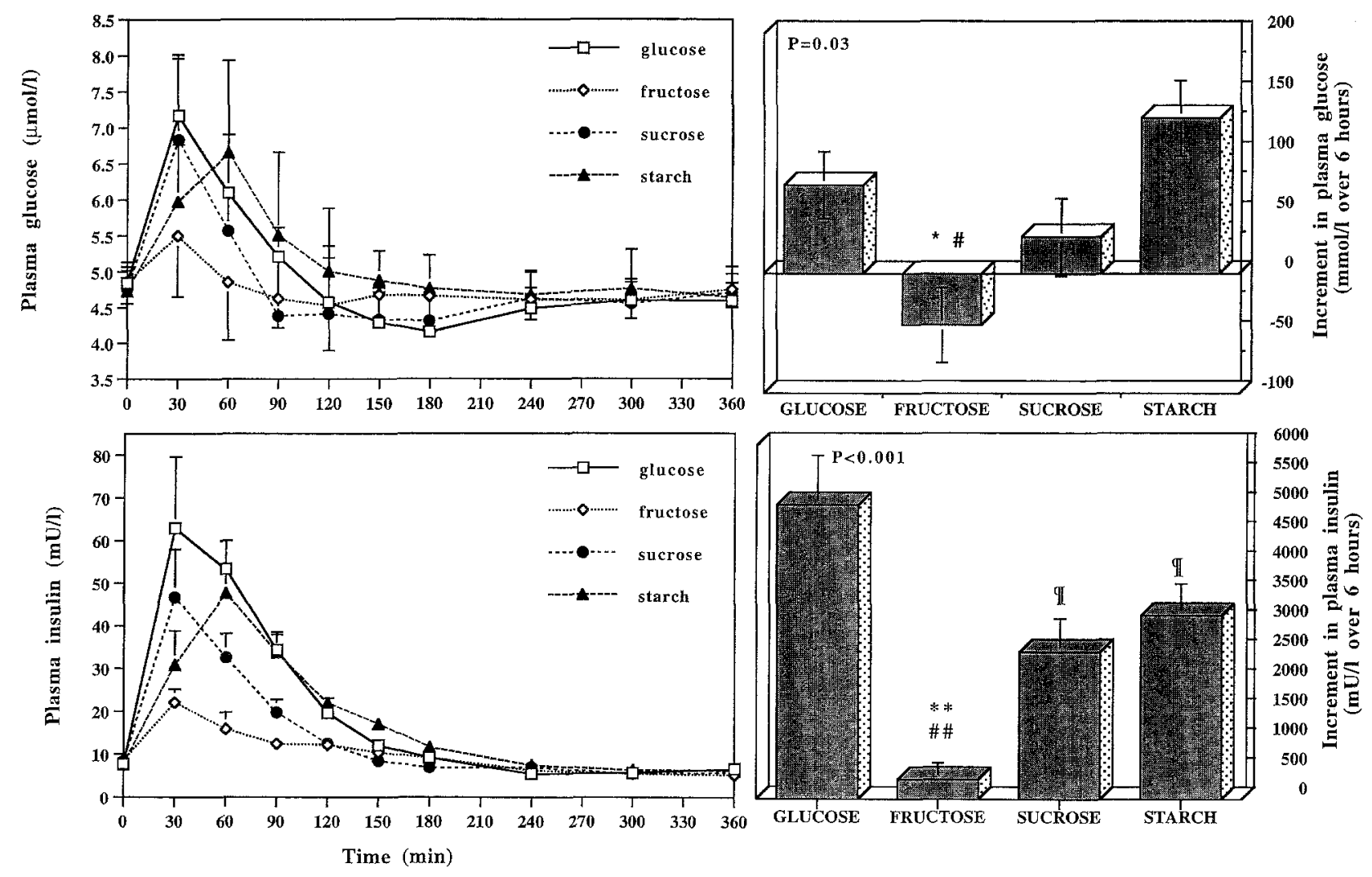

Fig 1. Plasma glucose and insulin concentrations after ingestion of different dietary carbohydrates (left) and integrated responses over 6 hours (right). Results are the mean $\pm \mathrm{SE} ; \mathbf{n}=10$. Statistical significance is only indicated in figure for differences in integrated responses between carbohydrates. ANOVA: integrated glucose response, $P=.03$; integrated insulin response, $P<.001$. Wilcoxon test: $\llbracket P<.01 v$ glucose ingestion; ${ }^{*} P<.05$ and ${ }^{* *} P<.01 v$ glucose and starch ingestion; \#P<.05 and \#\#P<.01v sucrose ingestion. 

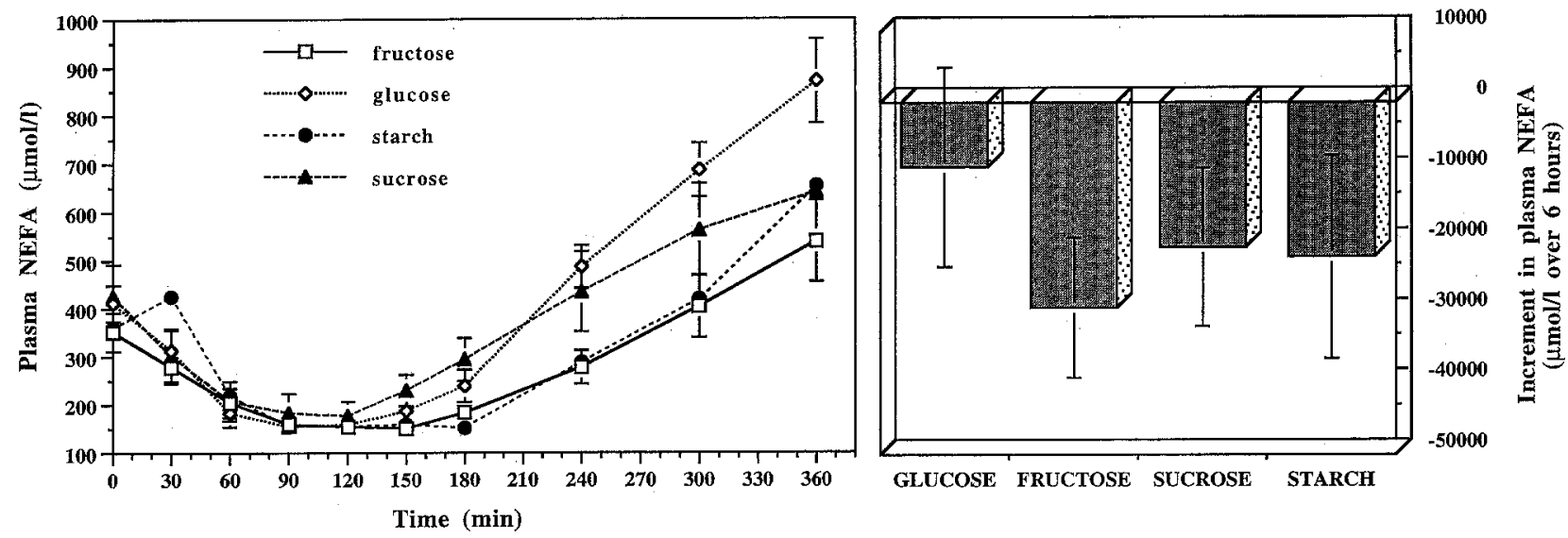

Fig 2. Plasma NEFA levels after ingestion of different dietary carbohydrates (left) and integrated responses over 6 hours (right). Results are the means $\pm S E ; n=10$.

similar results (for glucose $8.0 \% \pm 1.7 \%$, for fructose $11.1 \% \pm 2.1 \%$, for starch $8.2 \% \pm 1.8 \%$, and for sucrose $11.4 \% \pm 1.4 \%$; ANOVA, $P=.017$ ). In Table 1 , thermogenic effects of the different carbohydrates are summarized.

\section{Substrate Utilization}

Carbohydrate oxidation. Basal carbohydrate oxidation was not significantly different in the four experiments $(0.088 \pm 0.014 \mathrm{~g} / \mathrm{min})$. With all carbohydrate loads, there was a significant increase in carbohydrate oxidation (ANOVA, $P<.001$; Fig 4A). Carbohydrate oxidation increased with fructose and sucrose ingestion to maximum values of $0.263 \pm 0.014$ and $0.260 \pm 0.022 \mathrm{~g} / \mathrm{min}$, respectively, at 60 minutes, whereas the peak increment with glucose and starch occurred later and was significantly less (glucose at 120 minutes, $0.178 \pm 0.016 \mathrm{~g} / \mathrm{min}$, and starch at 150 minutes, $0.179 \pm 0.022 \mathrm{~g} / \mathrm{min}$; fructose and sucrose $v$ starch and glucose, $P<.01$ ). A return to baseline levels occurred at 210 minutes for glucose, starch, and sucrose, and at 240 minutes for fructose. There were significant differences in total carbohydrate oxidation over 6 hours between carbohydrates (ANOVA, $P=.008$; Fig 4C). Post hoc testing showed significantly higher integrated total carbohydrate oxidation with fructose $(55.5 \pm 4.0 \mathrm{~g} / 6 \mathrm{~h})$ and sucrose $(48.4 \pm 5 \mathrm{~g} / 6 \mathrm{~h})$ as compared with glucose $(37.1 \pm 5.0 \mathrm{~g} / 6 \mathrm{~h})$ and $\operatorname{starch}(38.0 \pm 5.0 \mathrm{~g} / 6 \mathrm{~h} ;$ Fig $4 \mathrm{C})$. Exogenous carbohydrate oxidation (amount of ingested carbohydrate directly oxidized) showed a pattern similar to that for total carbohydrate oxidation (Fig 4B and C). The peak increase in exogenous carbohydrate oxidation occurred later than the peak increase in total carbohydrate oxidation, which cannot be interpreted as a preferential oxidation of endogenous versus exogenous carbohydrates, but may be explained by dilution of $\left[{ }^{13} \mathrm{C}\right]$ glucose in the endogenous glucose pool and further dilution of ${ }^{13} \mathrm{CO}_{2}$ in the bicarbonate pool, as previously reported. ${ }^{15}$ For all carbohydrates, there was a significant increase in exogenous carbohydrate oxidation (ANOVA, $P<.001$ ). Both the peak increase $(P<.001 ;$ Fig $4 \mathrm{~B})$ and the integrated exogenous carbohydrate oxidation over 6 hours $(P<.001$; Fig 4C) were significantly higher with fructose $(28.8 \pm 0.9$ $\mathrm{g} / 6 \mathrm{~h})$ and sucrose $(25.9 \pm 1.1 \mathrm{~g} / 6 \mathrm{~h})$ in comparison to glucose $(19.6 \pm 0.9 \mathrm{~g} / 6 \mathrm{~h})$ and starch $(18.2 \pm 1.1 \mathrm{~g} / 6 \mathrm{~h})$. In addition, exogenous carbohydrate oxidation was higher with fructose as compared with sucrose $(P<.01)$. By subtracting the cumulated exogenous carbohydrate oxidation from the cumulated total carbohydrate oxidation, an

Table 1. Overview of the Increments in Integrated Metabolic Responses After Ingestion of Glucose, Fructose, Sucrose, and Starch

\begin{tabular}{|c|c|c|c|c|c|c|c|}
\hline \multirow[b]{2}{*}{ Carbohydrate } & \multirow{2}{*}{$\begin{array}{c}\text { Glucose } \\
\text { Response } \\
\text { (mmol/L } \cdot 6 \mathrm{~h})\end{array}$} & \multirow{2}{*}{$\begin{array}{c}\text { Insulin } \\
\text { Response } \\
(\mathrm{mU} / \mathrm{L} \cdot 6 \mathrm{~h})\end{array}$} & \multirow{2}{*}{$\begin{array}{c}\text { NEFA } \\
\text { Response } \\
(\mu \mathrm{mol} / \mathrm{L} \cdot 6 \mathrm{~h})\end{array}$} & \multirow{2}{*}{$\begin{array}{c}\Delta \mathrm{EE} \\
\langle\mathrm{kJ} / 6 \mathrm{~h}\rangle\end{array}$} & \multicolumn{2}{|c|}{$\mathrm{CHO}_{\mathrm{ox}}(\mathrm{g} / 6 \mathrm{~h})$} & \multirow{2}{*}{$\begin{array}{c}\text { Fat } \\
\text { Oxidation } \\
(\mathrm{g} / 6 \mathrm{~h})\end{array}$} \\
\hline & & & & & Endogenous & Exogenous & \\
\hline Glucose & $74 \pm 28$ & $4,991 \pm 844$ & $-9,152 \pm 14,134$ & $94 \pm 20$ & $17.5 \pm 4.9$ & $19.6 \pm 0.9$ & $-5.1 \pm 0.9$ \\
\hline Fructose & $-43 \pm 31 \neq \|$ & $343 \pm 281 \S \pi$ & $-29,129 \pm 9,962$ & $130 \pm 24$ & $26.6 \pm 13.0$ & $28.8 \pm 0.95$ & $-13.9 \pm 3.0^{*}$ \\
\hline Sucrose & $31 \pm 32$ & $2,495 \pm 568 t$ & $-20,536 \pm 11,266$ & $141 \pm 17 \ddagger$ & $22.5 \pm 4.6$ & $25.9 \pm 1.1 \S$ & $-8.5 \pm 2.5$ \\
\hline Starch & $130 \pm 32$ & $3,114 \pm 541 \dagger$ & $-21,912 \pm 14,412$ & $108 \pm 24$ & $19.8 \pm 4.7$ & $18.2 \pm 1.1$ & $-5.4 \pm 2.0$ \\
\hline ANOVA & $\rho=.03$ & $P<.001$ & NS. & $P=.016$ & NS & $P<.001$ & $P=.056$ \\
\hline
\end{tabular}

NOTE. Results are the means $\pm \mathrm{SE} ; \mathrm{n}=10$. Comparisons made by Wilcoxon test.

Abbreviations: $\triangle \mathrm{EE}$, EE above baseline; $\mathrm{CHO}_{\text {ox }}$, carbohydrate oxidation.

${ }^{*} P<.05,+P<.01: v$ glucose ingestion.

$\ddagger P<.05, \$ P<.01: v$ glucose and starch ingestion.

$\| P<.05, \uparrow P<.01: v$ sucrose ingestion. 

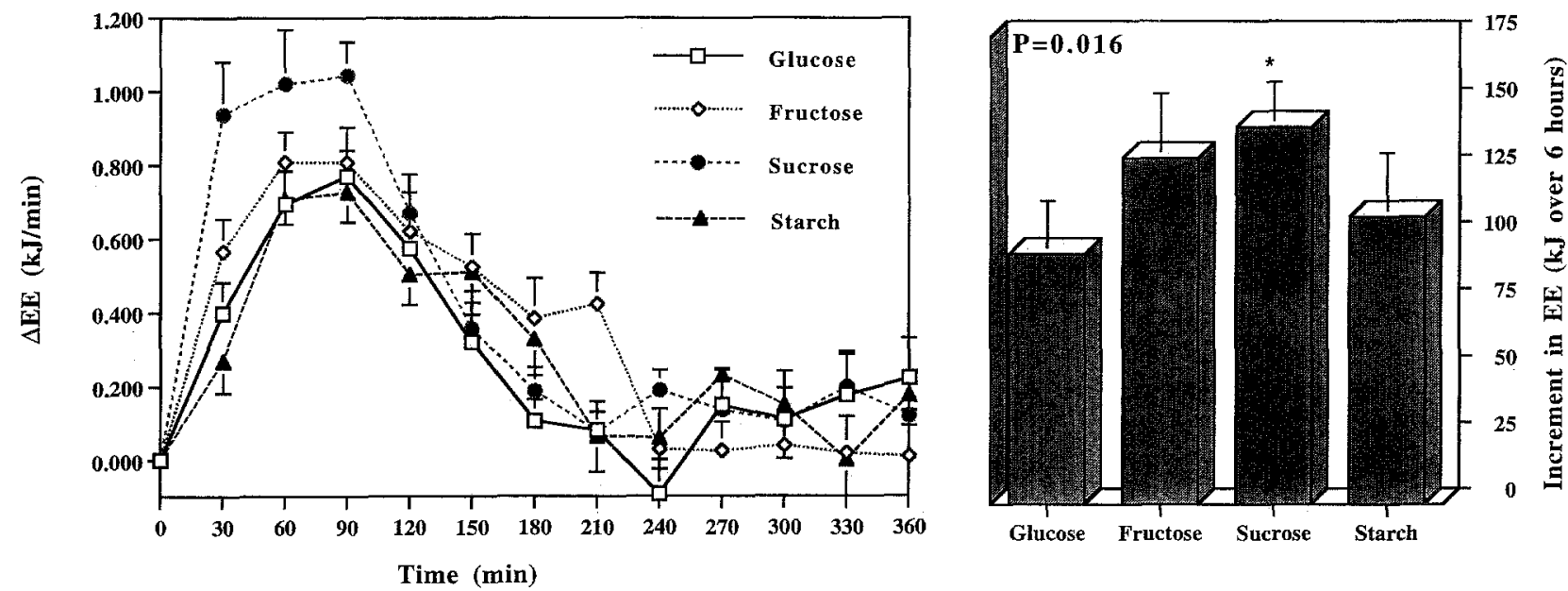

Fig 3. EE after ingestion of different dietary carbohydrates (left) and integrated responses over $\mathbf{6}$ hours (right). Results are the mean $\pm \mathbf{S E}$; $\mathbf{n}=$ 10. Statistical significance is only indicated in figure for differences in integrated responses between carbohydrates. ANOVA: integrated response, $P=.016$. Wilcoxon test: ${ }^{*} P<.05 \mathrm{v}$ glucose and starch ingestion; $P=.059$, fructose $v$ glucose.

indication of the contribution of endogenous glycogen stores to total carbohydrate oxidation can be obtained (Fig 4C). Also, the cumulated endogenous carbohydrate oxidation tended to be higher with fructose $(26.6 \pm 4.1 \mathrm{~g} / 6 \mathrm{~h})$ and sucrose $(22.5 \pm 4.6 \mathrm{~g} / 6 \mathrm{~h})$ as compared with glucose $(17.5 \pm 4.9 \mathrm{~g} / 6 \mathrm{~h})$ and starch $(19.8 \pm 4.7 \mathrm{~g} / 6 \mathrm{~h})$, but the differences did not reach statistical significance. In Table 1 , data on endogenous and exogenous carbohydrate oxidation are summarized.

Lipid oxidation. Basal fat oxidation was comparable on the four occasions $(0.072 \pm 0.007 \mathrm{~g} / \mathrm{min}$; Fig 5). After all carbohydrate loads, there were significant changes in lipid oxidation (ANOVA, $P<.001$ ). The highest initial decrements occurred with fructose and sucrose (at 30 minutes, $-0.008 \pm 0.008 \mathrm{~g} / \mathrm{min}$, and at 60 minutes, $0.007 \pm 0.01$ $\mathrm{g} / \mathrm{min}$, respectively), whereas the decrement occurred later and was less pronounced with starch (at 150 minutes, $0.033 \pm 0.008 \mathrm{~g} / \mathrm{min}$ ) and glucose (at 120 minutes, $0.017 \pm 0.01 \mathrm{~g} / \mathrm{min} ;$ fructose and sucrose $v$ starch and glucose, $P<.01$ ). After the decrement, lipid oxidation returned to baseline for fructose and sucrose at 210 minutes and for glucose and starch at 270 minutes. There was a strong tendency for differences in the integrated changes in lipid oxidation above baseline over 6 hours between the different carbohydrates $(P=.056)$. Post hoc testing showed a significantly higher decrement in lipid oxidation with fructose as compared with glucose $(P<.05)$ and a tendency toward a higher decrement with fructose as compared with starch $(P=.075)$. In Table 1 , an overview of the main findings of the present study is presented.

\section{DISCUSSION}

During the last few decennia, attention has focused on the role of the carbohydrate to fat ratio of the diet in the maintenance of energy balance and regulation of body weight, ${ }^{1,2}$ since for a condition of energy balance the macronutrient composition of the diet must equal the fuel mix oxidized by the body. The body's regulatory mechanisms are capable of efficiently adjusting carbohydrate oxidation to intake, whereas the capacity to regulate shortterm fat balance is limited. Adjustment of fat oxidation to intake may only occur over extended periods by changes in body fat mass and subsequent changes in circulating fatty acids and fat oxidation, whereas short-term fat oxidation is merely dependent on factors related to carbohydrate metabolism, such as body glycogen stores, rather than on fat intake. In considering the role of carbohydrates in body weight regulation, it must be taken into account that variations exist in the absorption pattern of carbohydrates from the gut and in the subsequent nutrient and hormonal responses and thermogenic responses. ${ }^{4}$ The present study was intended to investigate postprandial thermogenesis and substrate utilization after ingestion of different dietary carbohydrates in healthy lean males. The results show distinct differences in insulinemic, glycemic, nutrient, and thermogenic responses after ingestion of different carbohydrate sources and pronounced differences in these metabolic variables when responses are integrated over 6 hours, implying that the carbohydrate composition of the diet may have important consequences for overall energy and macronutrient balance.

The thermic response to carbohydrate ingestion was comparable after sucrose and fructose, higher with sucrose than with glucose and starch, and higher with fructose than with glucose. Rothwell and Stock ${ }^{16}$ previously reported a diminished meal-induced thermogenic response in cafeteriafed diabetic rats, which normalized again after administration of insulin. On basis of these studies, insulin has been considered an important determinant of diet-induced thermogenesis. The finding in the present study that sucrose and fructose result in the highest thermogenic responses and lowest insulinemic responses indicates that thermogenesis after carbohydrate ingestion is not dependent on an increase in plasma insulin concentration per se but is 


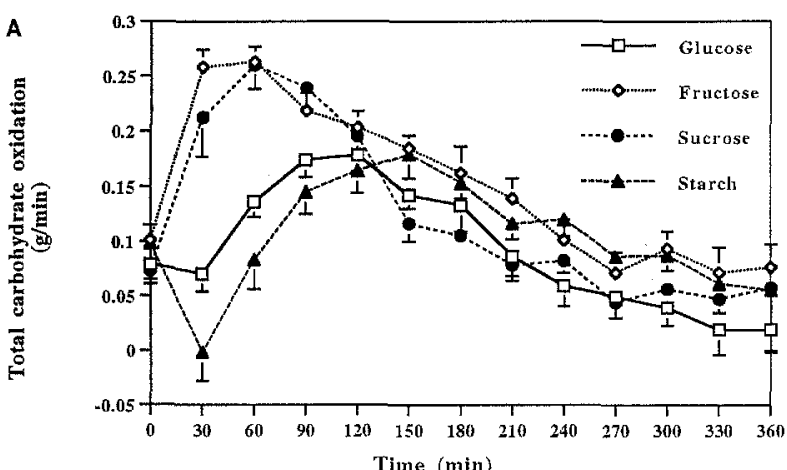

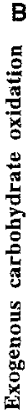

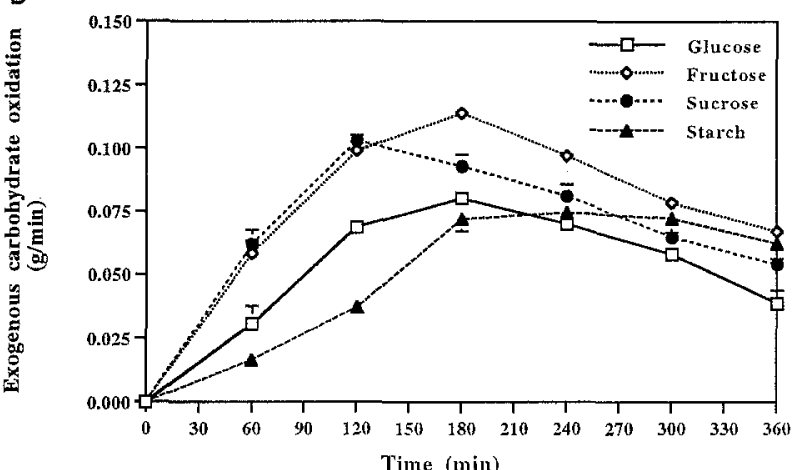

$c$

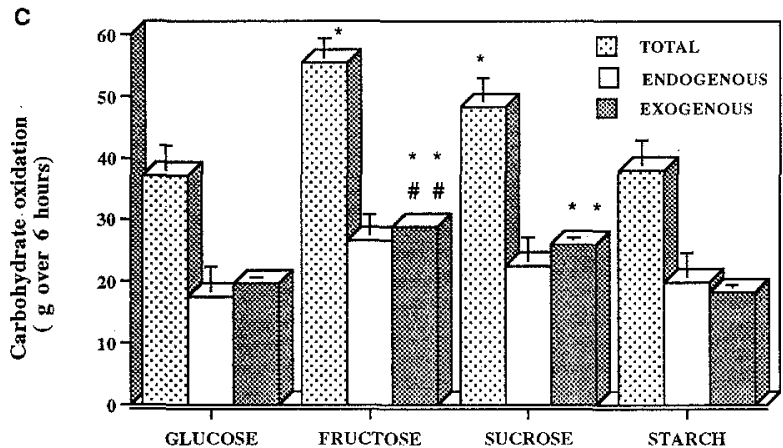

Fig 4. Total (A) and exogenous (B) carbohydrate oxidation after ingestion of different dietary carbohydrates and integrated responses of total, endogenous, and exogenous oxidation over 6 hours (C). Results are the mean $\pm S E ; n=10$. Statistical significance is only indicated in figure for differences in integrated responses between carbohydrates. ANOVA: integrated total carbohydrate oxidation response, $P=.008$; integrated exogenous oxidation, $P<.001$. Wilcoxon test: ${ }^{*} P<.05$ and $* * P<.01 v$ glucose and starch; \#\#P<.01 v sucrose.

secondary to an augmentation of cellular metabolism. This concept is supported by other studies. ${ }^{17-19}$ Cristin et al ${ }^{17}$ showed that insulin per se did not stimulate thermogenesis to a great extent, but that via sympathetic nervous stimulation it could explain the facultative component (EE above obligatory costs for absorption, digestion, and storage of nutrients) of the diet-induced thermogenesis. In addition, it has been documented in other studies that the impairment in the thermic effect of glucose in obesity and type II diabetes is related to the magnitude of insulin resistance and consequently a lower rate of insulin-mediated glucose uptake. ${ }^{18,19}$ Moreover, infusion of sufficient amounts of insulin to obtain rates of glucose metabolism equal to levels in normal volunteers resulted in normalization of the thermogenic response. ${ }^{19}$

A higher thermogenic response with sucrose and fructose as compared with glucose $e^{5-8}$ has been reported previously and is ascribed to differences in postingestive substrate utilization. Both the peak increases and integrated responses over 6 hours for total carbohydrate oxidation and exogenous carbohydrate oxidation were significantly higher with fructose and sucrose in comparison to glucose and starch, and a more pronounced initial decrement in lipid oxidation occurred with sucrose and fructose. The higher thermogenesis and carbohydrate oxidation is probably related to particularities of fructose metabolism in the liver. The more rapid and greater increase in carbohydrate oxidation may be explained by the finding that fructokinase, the enzyme responsible for phosphorylating fructose, is approximately 10 times as active as the combined activities of glucokinase and hexokinase, required for glucose phosphorylation. ${ }^{20}$ In addition, fructose avoids the first ratelimiting enzymes of glycolysis (in particular, phosphofructokinase), resulting in a quicker metabolism and accumulation of three-carbon components available for gluconeogenesis and glycogen storage. ${ }^{21}$ Despite an increased carbohydrate oxidation with fructose, leaving less fructose available for storage, it has been previously reported that fructose is also a better substrate for hepatic glycogen synthesis. ${ }^{22}$ Liver glycogen formation from fructose involves its cleavage to three-carbon compounds and subsequent glycogen formation (requiring four molecules of adenosine triphosphate [ATP]), whereas glucose can be converted directly to glycogen (requiring two ATP) or converted via threecarbon compounds to glycogen (requiring four $\mathrm{ATP}^{23}$ ). Consequently, glycogen synthesis from fructose requires more energy in comparison to glycogen formation from glucose, and may thereby be of importance in the higher thermogenic response with fructose and sucrose as compared with glucose and starch. Furthermore, it has previously been reported that, besides glycolysis, fructose stimulates glycogen formation and also gluconeogenic pathways (due to a low insulinemic response with fructose and sucrose), resulting in an activation of opposing pathways, whereas after glucose ingestion an inhibition of gluconeogenesis occurs. ${ }^{5}$ This occurrence of futile cycling may also (partly) explain the higher thermogenesis due to the fructose component. The finding in the present study that the contribution of endogenous carbohydrate stores to total carbohydrate oxidation tended to be higher with fructose and sucrose as compared with starch and glucose may support the concept of an increased futile cycling with fructose and sucrose (increased glycogen formation $v$ increased breakdown). However, care should be used in interpreting these results, since the differences in endogenous carbohydrate oxidation did not reach statistical significance due to a large variation.

It has been previously suggested that fructose and sucrose may have a more pronounced stimulating effect on lipid synthesis (energy cost $=24 \%$ of energy cost for glucose precursor ${ }^{23}$ ) than glucose. Indeed, with fructose at 30 and 60 minutes, the mean nonprotein respiratory ex- 

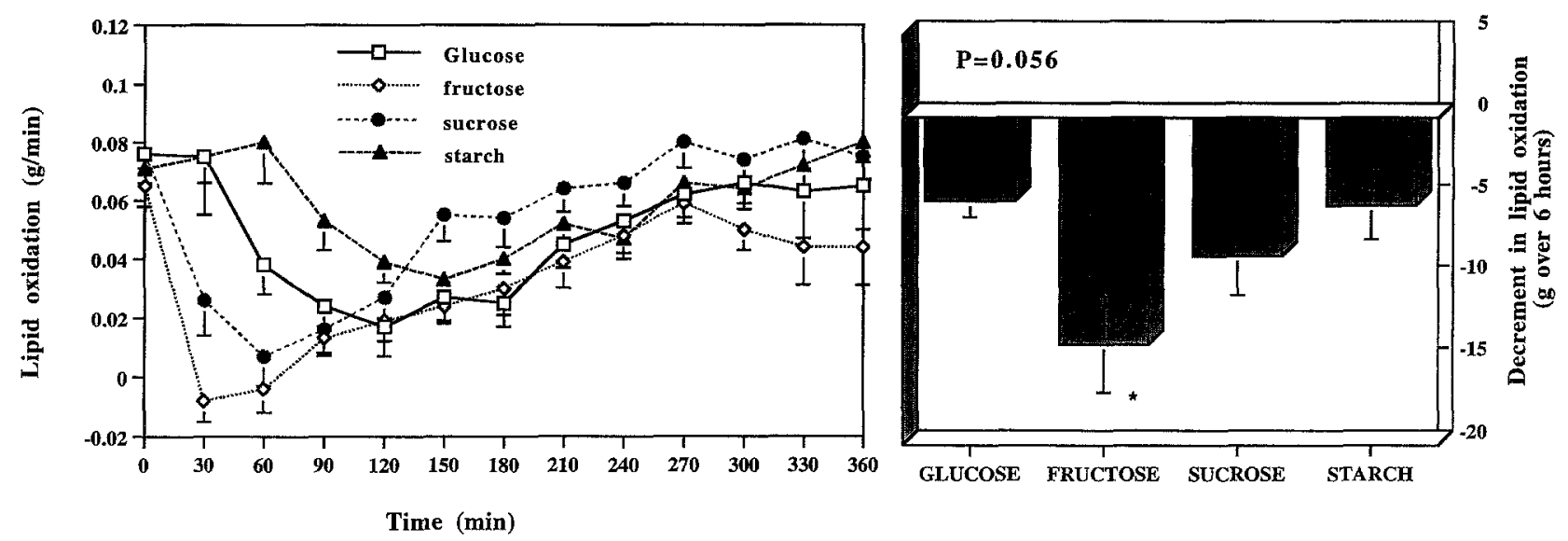

Fig 5. Lipid oxidation after ingestion of different dietary carbohydrates (left) and integrated responses over 6 hours (right). Results are the mean $\pm \mathrm{SE} ; \mathbf{n}=10$. Statistical significance is only indicated in figure for differences in integrated responses between carbohydrates. ANOVA: integrated lipid oxidation response, $P=.056$. Wilcoxon test: ${ }^{*} P<.05 \mathrm{v}$ glucose; $P=.075$, fructose $v$ starch.

change ratio was greater than 1 , indicating net lipogenesis (and slightly negative values for lipid oxidation). For this reason, we cannot exclude that lipogenesis contributed to some extent to the initial higher thermogenic response after fructose ingestion, but the contribution of this process to the total thermogenic response was probably not substantial in the present study. Moreover, with sucrose ingestion, the mean nonprotein respiratory exchange values were not greater than 1 during 6 hours postprandially, indicating that the contribution of lipogenesis to the increased sucroseinduced thermogenic response is negligible.

Blood glucose and insulin values showed a delayed peak and a slower return to baseline with starch as compared with glucose, sucrose, and fructose, which may be related to a slower rate of gastric emptying, digestion, or absorption with starch than with the other carbohydrates. However, no significant differences were apparent in the 6-hour thermogenic response and substrate utilization between starch and glucose, indicating that a (slightly) different rate of digestion does not necessarily lead to differences in postingestive energy and substrate metabolism. In this study, we used a pregelatinized good digestible corn starch (73\% amylopectin and $27 \%$ amylose), which makes it uncertain whether these results can be extrapolated to less well digestible starches with more blunted glucose and insulin responses. Our results seem to be in contrast with the higher overall fat oxidation reported after glucose ingestion in comparison to manioc starch ingestion, ${ }^{9}$ which may be due to the different type of starch used in the latter study. However, Würsch et $\mathrm{a}^{24}$ reported a similar substrate oxidation and EE over 6 hours after a bean meal and a potato meal, whereas glucose and insulin responses were significantly blunted after the bean meal, indicating no effect of rate of digestion on energy and substrate metabolism. Determining the effect of starch type and rate of digestion on postprandial thermogenic and nutrient responses requires further research.

What nutritional implications do the present findings have? Using fructose and sucrose as a carbohydrate source in the diet may have advantageous effects on 24-hour EE (higher thermogenesis) in young lean males, resulting in a better ability to maintain a condition of energy balance. The higher thermogenic response and higher carbohydrate oxidation with sucrose and fructose together with the relatively low glycemic and insulinemic response may be an advantage for using fructose and sucrose as part of the diet in insulin-resistant or diabetic subjects, since in these subjects both a decreased carbohydrate oxidation and a blunted thermogenic response have been reported. ${ }^{18,19}$ However, data on the effect of these carbohydrates on glucose tolerance and insulin resistance are controversi$\mathrm{al}^{25-27}$ and further controlled studies are required to elucidate whether the present findings in healthy lean males can be extrapolated to insulin-resistant or diabetic subjects. Moreover, the higher carbohydrate oxidation with fructose and sucrose was accompanied by a more pronounced initial suppression of lipid oxidation. In view of the inability of the body to regulate short-term fat balance, a more pronounced suppression of fat oxidation would be a disadvantageous effect leading to a positive fat balance and an increase of body fat stores over longer periods. When the changes in fat oxidation are integrated over 6 hours postprandially, there is a larger decrease in fat oxidation with fructose as compared with glucose and starch, whereas the integrated decrease in fat oxidation with sucrose is less pronounced and not significantly different from that obtained with glucose and starch. These findings suggest that with respect to fat balance regulation, sucrose is preferable to fructose as a carbohydrate source. When considering these results, the question arises as to whether these findings obtained after ingestion of liquid carbohydrate loads can be extrapolated to a situation in which carbohydrates are ingested in a meal. Support for an affirmative answer comes from studies by Raben et $\mathrm{al}^{28}$ and Schwartz et $\mathrm{al}^{6}$ in which fructose incorporated in a meal yields metabolic responses similar to those in the present study. Further studies must be performed to investigate the effects of incorporation of different carbohydrate sources in the diet on long-term (measured in days) energy and macronutrient balance. 


\section{REFERENCES}

1. Astrup A, Raben A: Obesity: An inherited deficiency in the control of macronutrient balance. Eur J Clin Nutr 46:611-620, 1992

2. Flatt JP: Use and storage of carbohydrate and fat. Am J Clin Nutr 61:952S-959S, 1995 (suppl)

3. Schutz Y, Jéquier E: Failure of dietary fat intake to promote fat oxidation: A factor favoring the development of obesity. Am J Clin Nutr 50:307-314, 1989

4. Wolever TMS, Jenkins DJA, Collier GR, et al: Metabolic response to test meals containing different carbohydrate foods: I. Relationship between rate of digestion and plasma insulin response. Nutr Res 8:573-582, 1988

5. Schwarz JM, Acheson KJ, Tappy L, et al: Thermogenesis and fructose metabolism in humans. Am J Physiol 262:E591-E598, 1992

6. Schwartz JM, Schutz Y, Piolino V, et al: Thermogenesis in obese women: Effect of fructose vs glucose added to a meal. Am J Physiol 262:E394-E401, 1992

7. Tappy L, Randin JP, Felber JP, et al: Comparison of thermogenic effect of fructose and glucose in normal humans. Am J Physiol 250:E718-E724, 1986

8. MacDonald I: Dietary carbohydrate and energy balance. Prog Biochem Pharmacol 21:181-191, 1986

9. Ritz P, Krempf M, Claorec D, et al: Comparative continuous indirect calorimetry study of two carbohydrates with different glycemic indices. Am J Clin Nutr 54:855-859, 1991

10. Scrimgeour CM, Rennie MJ: Automated measurement of the concentration and ${ }^{13} \mathrm{C}$ enrichment in breath and blood samples using a Finnigan MAT breath gas analysis system. Biomed Environ Mass Spectrom 15:365-367, 1988

11. Weir JB: New methods for calculating metabolic rate with special reference to protein metabolism. J Physiol 109:1-9, 1949

12. Brouwer $E$ : On simple formulae for calculating the heat expenditure and the quantities of carbohydrate and fat oxidized in metabolism of men and animals, from gaseous exchange (oxygen intake and carbonic output) and urine N. Acta Physiol Pharmacol Neerlandica 6:795-802, 1957

13. Frayn KN: Calculation of substrate oxidation rates in vivo from gaseous exchange. J Appl Physiol 55:628-634, 1983

14. Mosora F, Lacroix M, Luyckx A, et al: Glucose oxidation in relation to the size of the oral glucose loading dose. Metabolism 30:1143-1149, 1981

15. Pallikarakis N, Sphiris N, Lefebvre $P$ : Influence of the bicarbonate pool and on the occurrence of ${ }^{13} \mathrm{CO}_{2}$ in exhaled air. Eur J Appl Physiol 63:179-183, 1991
16. Rothwell NJ, Stock MJ: A role for insulin in the dietinduced thermogenesis of cafeteria fed rats. Metabolism 30: 673-678, 1981

17. Cristin L, Nacht CA, Vernet $O$, et al: Insulin: Its role in the thermic effect of glucose. J Clin Invest 77:1747-1755, 1986

18. Golay A: Blunted glucose-induced thermogenesis: A factor contributing to the relapse of obesity. Int J Obes 17:S23-S27, 1993 (suppl 1)

19. Ravussin E, Acheson KJ, Vernet O, et al: Evidence that insulin resistance is responsible for the decreased thermic effect in human obesity. J Clin Invest 76:1268-1273, 1985

20. Mayes PA, Laker ME: Effects of acute and long term fructose administration on liver metabolism. Prog Biochem Pharmacol 21:33-58, 1986

21. Henry RR, Crapo PA: Current issues in fructose metabolism. Annu Rev Nutr 11:21-39, 1991

22. Nilsson LH, Hultman E: Liver and muscle glycogen in man after glucose and fructose infusion. Scand J Lab Invest 33:5-10, 1974

23. Flatt JP: The biochemistry of energy expenditure, in Recent Advances in Obesity Research, vol 2. London, UK, Newman, 1978, pp 211-228

24. Würsch $P$, Acheson K, Koellreutter B, et al: Metabolic effects of instant bean and potato over 6 hours. Am $J$ Clin Nutr 48:1413-1423, 1988

25. Bantle JP, Swanson JE, Thomas W, et al: Metabolic effects of dietary sucrose in type II diabetic subjects. Diabetes Care 16:1301-1305, 1993

26. Coulston AM, Hollenbeck CB, Donner CC, et al: Metabolic effects of added dietary sucrose in individuals with non-insulindependent diabetes mellitus (NIDDM). Metabolism 34:962-966, 1985

27. Piatti PM, Pontiroli AR, Saibene A, et al: Insulin sensitivity and lipid levels in obese subjects after slimming diets with different complex and simple carbohydrate content. Int J Obes 17:375-381, 1993

28. Raben A, Kiens B, Richter EA: Differences in glycemia, hormonal response and energy expenditure after a meal rich in mono- and disaccharides compared to a meal rich in polysaccharides in physically fit and sedentary subjects. Clin Physiol 14:267-280, 1994 